International Journal of Engineering, Science and Technology

Vol. 2, No. 8, 2010, pp. 25-32
INTERNATIONAL

JOURNAL OF

ENGINEERING,

SCIENCE AND

TECHNOLOGY

www.ijest-ng.com

(C) 2010 MultiCraft Limited. All rights reserved

\title{
Chemical phases of some of the Ayurvedic heamatinic medicines
}

\author{
Amita Tripathi $^{1 * \#}$, Bhavna Joshi ${ }^{1}$, H.S. Singh ${ }^{1}$, J.S. Rathore ${ }^{2}$,Giriraj Sharma ${ }^{3}$ \\ ${ }^{1 *}$ Department of Physics, J.N.V. University, Jodhpur, INDIA \\ ${ }^{2}$ Department of Chemistry, J.N.V. University, Jodhpur, INDIA \\ ${ }^{3}$ Community Health Center, Rohat, Pali, INDIA \\ *Corresponding Author: e-mail: tripathi_amita@yahoo.com \\ "Present Address: GSI, WR, Jaipur
}

\begin{abstract}
Chemical phases of iron in some of the Ayurvedic medicines are investigated through Mössbauer Spectroscopy and FTIR. In all the four medicines studied, iron is found in oxide form, either $\mathrm{Fe}_{2} \mathrm{O}_{3}$ or $\mathrm{Fe}_{3} \mathrm{O}_{4}$ or both. The size distribution of iron particles is different for different medicines. FTIR spectra are characteristically different for different drugs. These oxide particles are dispersed in a base probably consisting of ash of herbs or compound used as the medium for the preparation of these medicines which might control the efficacy and concentration of iron in these drugs.
\end{abstract}

Keywords: Mössbauer Spectroscopy, FTIR, XRD, Ayurveda, heamatinic medicines

\section{Introduction}

Animals and humans need iron mainly to make hemoglobin, which delivers oxygen to the cells of body for production of energy. Iron is also needed to make myoglobin in muscles and to catalyze several enzymatic reactions in body (Tripathi et al, 1975). Humans can get iron from their food. But due to poor dietary habits, increase in demand (as during pregnancy) or due to some diseases the person may suffer from iron deficiency anemia. Due to anemia sufficient oxygen delivery to body cells is hampered causing many type of patho-physiological problems in the body. One of the major causes of mortality and morbidity is iron deficiency anemia.

Different 'systems of medicines' recommend different types of drugs in order to improve hemoglobin and ferritin. The commonly used allopathic medicines for treatment of iron deficiency anemia consist of various salts of iron like ferrous sulfates, ferrous fumerate, or ferrous gluconate etc. given in the form of tablets/syrup/injection.

Ayurveda is another system of medicine, originated in India several thousand years ago, which is gaining worldwide attention due to its much less side effects. For details one can refer ancient books like Charak Samhita-Sutra Sthana and Sushruta SamhitaSharir Sthana. In Ayurveda, iron and other metals are given in the form of bhasma (substance obtained by calcinations) prepared by heating raw material at high temperatures under predefined conditions. Preparation of bhasma is an elaborate process involving sodhana (purification), marana (detoxification) and bhasmikaran (process by which substance which are otherwise bioincompatible are made bio-compatible). The classical texts of Ayurveda prescribe in great detail the way the above processes need to be performed. Metals are first purified through a process called sodhana, during which the metal is repeatedly heated and cooled in herbal extracts which forms the matrix in which the metal is dispersed. Marana involves grinding of the material with appropriate herbal juice for extended periods, may be several weeks. This possibly reduces the particle size, increasing the surface area for quick chemical reactions. This is followed by bhasmikaran where the product of shodhana/marana is repeatedly triturated with herbs (bhavana) and calcined in closed earthen crucibles in a pit, to obtain bhasma. This process is repeated as many times as prescribed in the classical texts for each preparation. Hence we have dasa puta (10 cycles), satha puta (100 cycles), sahastra puta (1000 cycles), etc.

Though bhasma preparations are widely used in Ayurveda, practically nothing is known as to what chemical changes occur during the process of making bhasma. It is interesting to note that the same metal is processed with different sets of herbs, to be used for different indications/diseases. It would be very useful to study the mechanism by which the uptake of metal in the bhasma 
by the body takes place so that it gives the desired medicinal effect. As a first step, we investigate the chemical phases of iron present in some of the commercially available bhasmas. We have used Mössbauer spectroscopy as major research tool to characterize these irons containing bhasmas. For excellent review on the use of this technique in variety of fields we refer (Tominaga and Minai, 1984). Apart from Mössbauer studies we have also used FTIR and powder XRD to understand the phases.

At this initial stage of study we illustrate investigation carried out on four bhasmas viz Lauh bhasma, Lauh bhasma 100 putty, Swarn Makshik bhasma and Abhrak bhasma, although number of iron bearing Ayurvedic medicines are available but we restrict to these bhasma only: firstly, they are not only effective in treatment of anemia but also used in therapy of multiple diseases, secondly, these are readily available in market and thirdly these are cost effective. It is worth mentioning here that in order to get better insight into the chemical phases of these bhasmas we have collected the Mössbauer spectra of the different available brands of same medicine like Lauh bhasma of Dabur, Shree Baidyanath, Shree Mohata etc and even sample directly collected from local Rasayanshalla were also studied. However in this initial piece of work we have just displayed few representative spectra but it should be noted that the spectra obtained for same medicine belonging to different pharmaceutical company were identical.

\section{Experimental Details}

Mössbauer spectra of four commercially available Ayurvedic drug samples were obtained by using a conventional constant acceleration Mössbauer spectrometer with ${ }^{57} \mathrm{Co}$ in Rh matrix as the Mössbauer source. Mössbauer absorbers were prepared by sandwiching finely ground drug powder between two paper discs in a $25 \mathrm{~mm}$ diameter sample holder. Computer programme written by Meerwal and at IIT Kanpur were used after suitable modifications for fitting of room temperature spectra. The programs assume the spectrum to be a sum of Lorentzians. The isomer shift (IS) values are reported with respect to the centroid of a pure iron absorber. In most of the cases, the width and the intensity of two halves of a quadrupole doublet were considered to be equal. In case of sextets, intensity of first and sixth, second and fifth, and third and fourth lines, were considered to be equal. Also, widths of all the six lines were constrained to be equal. FTIR spectra of all the samples were recorded on Varian 600 using KBr Pellets. XRD analysis was carried out at Indian Institute of Technology, Delhi using Panalytical XRD system. $\mathrm{CuK}_{\alpha}$ target was used as the target while keeping the scan speed as $1.2^{0} / \mathrm{min}$.

\section{Results and Discussion}

Table 1 gives the description of the four drugs selected for the present study. As the drugs were purchased from the market, we do not have authentic record of their preparation process.

Table 1 Details of Ayurvedic medicines investigated

\begin{tabular}{|c|c|c|c|}
\hline S.No. & Sample & Company Name & $\begin{array}{c}\text { Batch No/ Date of } \\
\text { Mfg. }\end{array}$ \\
\hline 1. & Lauh bhasma & Shree Mohata, Bikaner & $76-55 / 5-2007$ \\
\hline 2. & $\begin{array}{c}\text { Lauh bhasma } \\
100 \text { putty }\end{array}$ & $\begin{array}{c}\text { Shree Baidyanath, } \\
\text { Allahabad }\end{array}$ & $101-26 / 6-2006$ \\
\hline 3. & $\begin{array}{c}\text { Swarnmakshik } \\
\text { bhasma }\end{array}$ & Shree Mohata, Bikaner & $36-26 / 2-2008$ \\
\hline 4. & Abhrak bhasma & $\begin{array}{c}\text { Shailendra Aushadh } \\
\text { Nirmanshala, Jodhpur }\end{array}$ & SH-01/3-2005 \\
\hline
\end{tabular}

Table 2 gives standard room temperature Mössbauer parameters (Mørup et al, 1985) for different oxide phases of iron which are commonly found in nature and also appear as end product when iron compounds are heated. This table will be helpful in interpreting our results. 
Table 2 Room Temperature Mössbauer Parameters of commonly occurring iron oxides

\begin{tabular}{|c|c|c|c|}
\hline $\begin{array}{c}\text { Name of } \\
\text { mineral }\end{array}$ & $\begin{array}{c}\text { Approximate range } \\
\text { of isomer shift (IS) } \\
\mathrm{mms}^{-1}\end{array}$ & $\begin{array}{c}\text { Approximate range of } \\
\text { quadrupole splitting (QS) } \\
\mathrm{mms}^{-1}\end{array}$ & $\begin{array}{c}\text { Approximate range of } \\
\text { Hyperfine magnetic field } \\
\text { (HMF) } \\
(\mathrm{T})\end{array}$ \\
\hline Hematite & $0.31-0.38$ & $-0.10--0.12$ & $50.7-51.5$ \\
\hline $\begin{array}{c}\text { Magnetite } \\
\text { A-site } \\
\text { B-site }\end{array}$ & 0.63 & 0.05 & 46.0 \\
\hline Goethite & 0.27 & $-0.10--0.14$ & 49.0 \\
\hline
\end{tabular}

\subsection{Lauh bhasma}

The XRD graphs of Lauh bhasma and Lauh bhasma 100 putty are shown in Figure 1. All the major peaks of the two patterns correspond to $\mathrm{Fe}_{2} \mathrm{O}_{3}$ crystal structure as indexed in the figure. The peak widths for Lauh bhasma 100 putty are sharper than the corresponding peaks of Lauh bhasma showing that repeated heating results in grain growth.

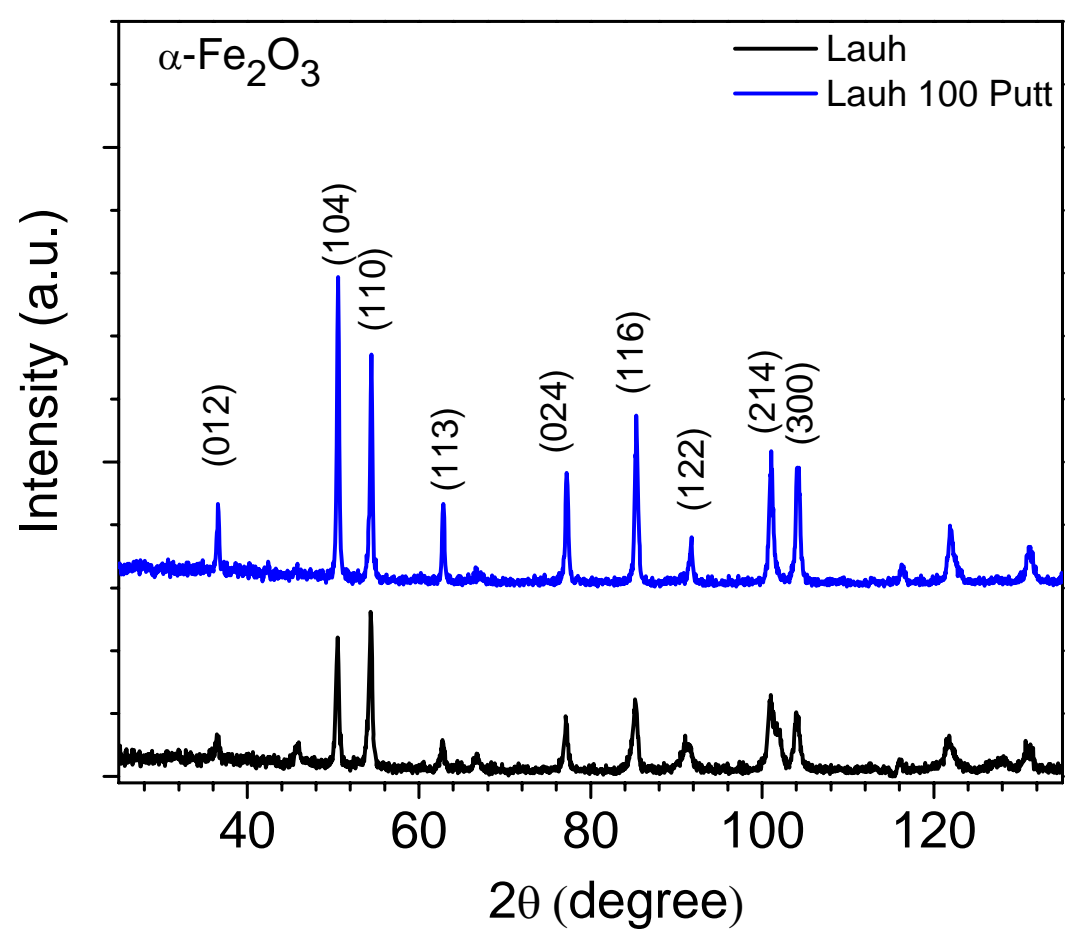

Figure 1 Powder XRD patterns of Lauh bhasma and Lauh bhasma 100 putty

In Figure 2 we display Mössbauer spectra of Lauh bhasma and Lauh bhasma 100 putty. The Mössbauer parameters obtained for these samples are given in Table 3. Though the XRD patterns of the two samples show pure $\mathrm{Fe}_{2} \mathrm{O}_{3}$ phases, their Mössbauer spectra are quite different. While the spectrum for Lauh bhasma 100 putty corresponds to a single sextet that for Lauh bhasma needs at least two sextets for reasonable fittings. Mössbauer parameters given in Table 3 show that both samples contain $\alpha-\mathrm{Fe}_{2} \mathrm{O}_{3}$ $(\mathrm{HMF} \approx 51 \mathrm{~T})$. While no other iron phase is found to be present in Lauh bhasma 100 putty, the sample of Lauh bhasma shows an additional sextet of somewhat lower HMF of 49.7 T. Such a sextet of lower HMF can show up if the particle size in the sample is such as to allow collective magnetic excitation where the particle's magnetic moment makes oscillations about an easy axis of magnetization. Thus the sample Lauh bhasma has iron in $\alpha-\mathrm{Fe}_{2} \mathrm{O}_{3}$ form but part of it is in fine particle form giving the additional sextet. The larger line width in the XRD of this sample supports this proposition. When the sample is repeatedly heated the grain growth is complete and we get single sextets of $\alpha-\mathrm{Fe}_{2} \mathrm{O}_{3}$ in the case of Lauh bhasma 100 putty. 

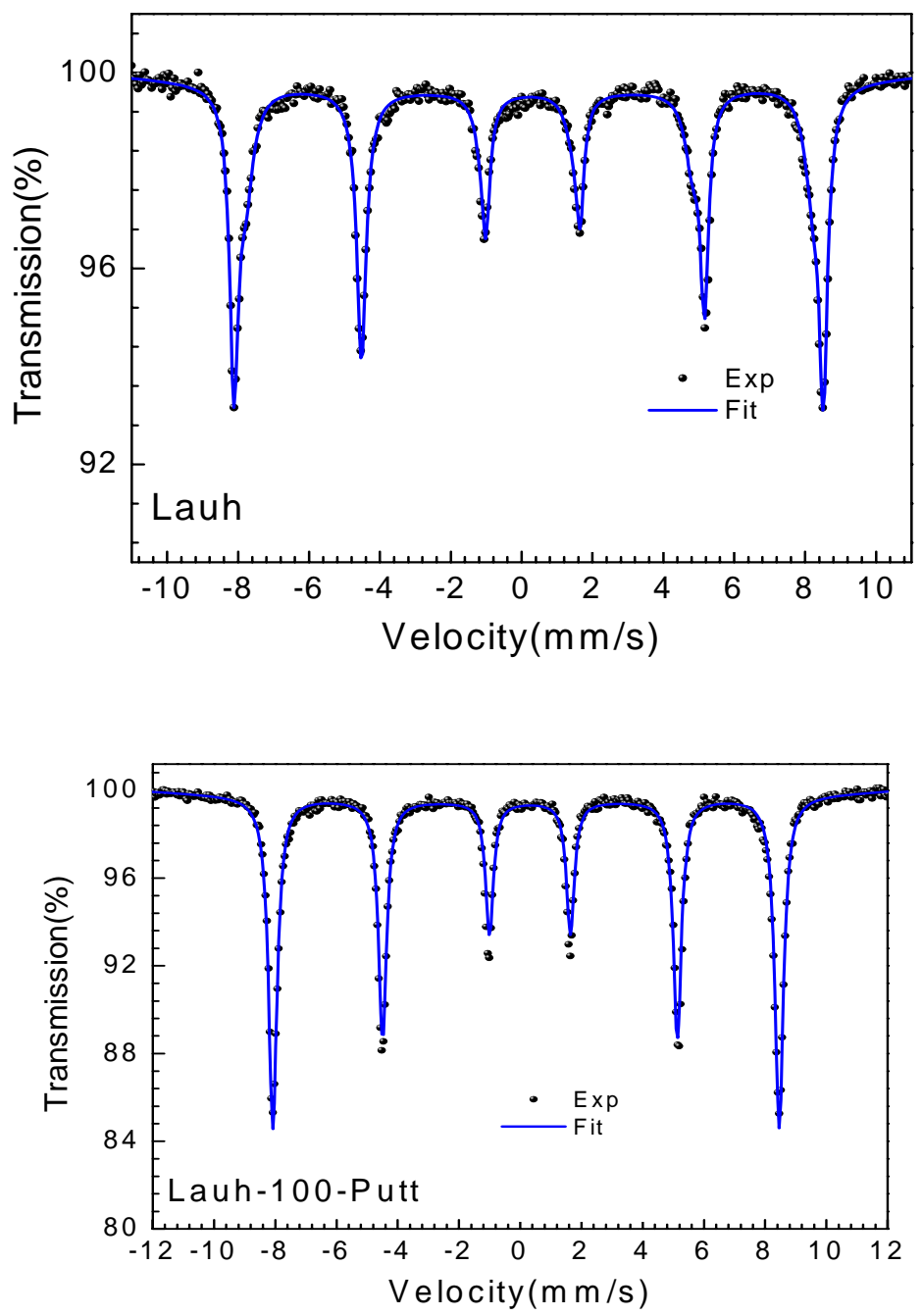

Figure 2 Mössbauer spectra of Lauh Bhasma and Lauh Bhasma 100 putty

Table 3 Mössbauer parameters of different medicine samples

\begin{tabular}{|c|c|c|c|c|c|c|}
\hline S.No. & Medicine Sample & Line & $\begin{array}{c}\text { IS } \\
\left(\mathrm{mms}^{-1}\right)\end{array}$ & $\begin{array}{c}\text { QS } \\
\left(\mathrm{mms}^{-1}\right)\end{array}$ & $\begin{array}{c}\text { HMF } \\
(\text { Tesla })\end{array}$ & $\begin{array}{c}\text { Relative Area } \\
(\%)\end{array}$ \\
\hline 1 & Lauh bhasma & Sextet-1 & 0.28 & 0.03 & 49.7 & 38.0 \\
& Sextet-2 & 0.35 & -0.06 & 51.7 & 62.0 \\
\hline 2 & Lauh bhasma 100 & Sextet-1 & 0.34 & -0.06 & 51.4 & 100 \\
& putty & & & & & \\
\hline 3 & Swarn Makshik & Sextet-1 & 0.41 & -0.16 & 51.6 & 54.2 \\
& bhasma & Sextet-2 & 0.19 & 0.03 & 49.8 & 28.8 \\
& Doublet-1 & 0.25 & 0.71 & - & 16.9 \\
\hline 4 & Abhrak bhasma & Sextet-1 & 0.37 & -0.20 & 46.7 & 93.5 \\
& & Doublet-1 & 0.13 & 0.52 & - & 7.9 \\
\hline
\end{tabular}


FTIR spectra of these two samples are given in Figure 3. Both the spectra show small intensity bands in the frequency range 400-500 $\mathrm{cm}^{-1}$ characteristic of iron in oxide phase (Palanivel and Velraj, 2007). A sharp band is also observed between 700-900 $\mathrm{cm}^{-1}$. Apart from this, FTIR spectra also exhibit presence of broad bands beyond $1000 \mathrm{~cm}^{-1}$. Intensity distribution in these higher wave number bands is quite different for the two samples. It appears that these bands correspond to the base material probably organic fraction (herbs) which is mixed in the drug during heating process.
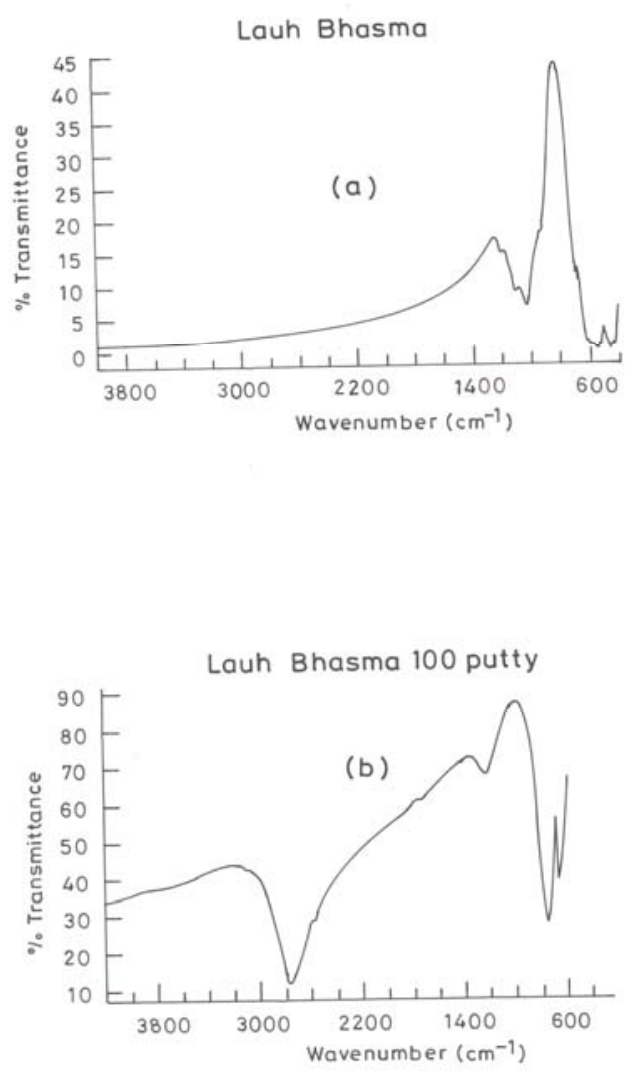

Figure 3. FTIR spectra of Lauh bhasma and Lauh bhasma 100 putty

The FTIR results thus show that iron is mainly present in oxide phase in both types of Lauh bhasma, consistent with our findings with XRD and Mössbauer spectroscopy. It appears that iron attains its final chemical phase, that is $\mathrm{Fe}_{2} \mathrm{O}_{3}$, in one cycle of heating only but the matrix in which this oxide is dispersed evolves continuously as more heating cycles are given. The fact that the pattern of absorption of the medicine in the body depends on the number of heating cycles of the bhasma, is then related to the role of the base material in response of the body with different kinds of diseases.

\subsection{Swarna Makshik bhasma}

When there is severe deficiency of iron in the body this drug is sometimes preferred. Though the name contains swarna (gold), this preparation does not contain gold. However it comes from a gold looking ore which contains iron in good proportion. Mössbauer spectrum obtained for this drug (Figure 4a) shows presence of two well grown sextets, one corresponding to alpha $\mathrm{Fe}_{2} \mathrm{O}_{3}$ and the other probably the same oxide with reduced particle size. This phase is close to what is observed in Lauh bhasma. However, unlike Lauh bhasma, a central doublet is also present in the Mössbauer spectrum of Swarn Makshik bhasma. This doublet is most likely coming from ultra fine oxide particles as these go through superparamagnetic relaxation with flipping time smaller than the measurement time of Mössbauer spectroscopy. This typically occurs for iron oxides when the particle size goes below $10 \mathrm{~nm}$. The presence of these ultra fine particles could be the reason of its increased efficacy making this drug more effective. It seems that the preparation leads to two distinctly different groups of particles one which have grown well and the other for which the grain growth is restricted. FTIR (shown in Figure 4b) shows intense bands characteristic of iron in oxide phase. Apart from these intense bands there are smaller peaks present in the range $1000-1200 \mathrm{~cm}^{-1}, 2300-2400 \mathrm{~cm}^{-1}$ and around 3400 $\mathrm{cm}^{-1}$. These bands can again be attributed to organic ash present in the sample. 

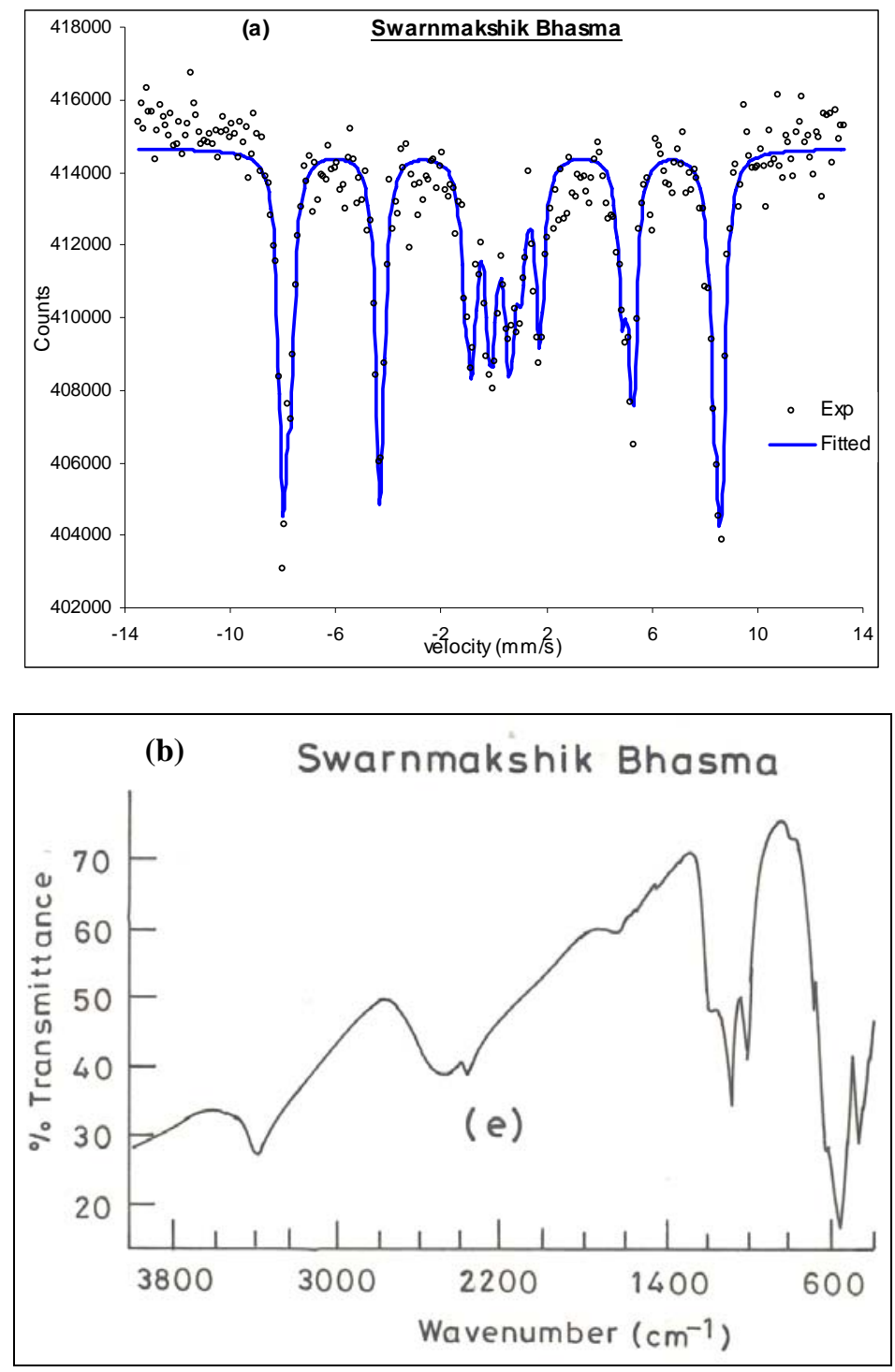

Figure 4 Mössbauer and FTIR Spectra of Swarn Makshik bhasma

\subsection{Abhrak bhasma}

Mössbauer spectrum for Abhrak bhasma is exhibited in Figure 5a. It exhibits relaxed Mössbauer pattern instead of full grown sextet obtained for other samples. Such a spectrum reveals that the whole sample is of nano size, though there will always be a size distribution. The presence of Abhrak (mica) during bhasmikaran step should be responsible for arresting the grain growth. The extensive study has been done by (Tripathi et al, 1978) on the decomposition pattern of iron rich mica like biotite from which these Abhrak bhasmas are prepared. In these studies and in many more studies it is established that when particle size is of the order of nano meters, instead of full grown sextet, a relaxed spectrum appears due to superparamagnetism. The relaxed Mössbauer spectra obtained in the present study indicate that most of the iron oxide particles in Abhrak bhasma are in nanometer size range. FTIR spectrum of Abhrak bhasma is displayed in Figure 5b. Several bands are obtained in the range $429-693 \mathrm{~cm}^{-1}$ which corresponds to oxide phases and apart from this two intense bands are present in the range $890-994 \mathrm{~cm}^{-1}$ which cannot be attributed to iron oxides. 

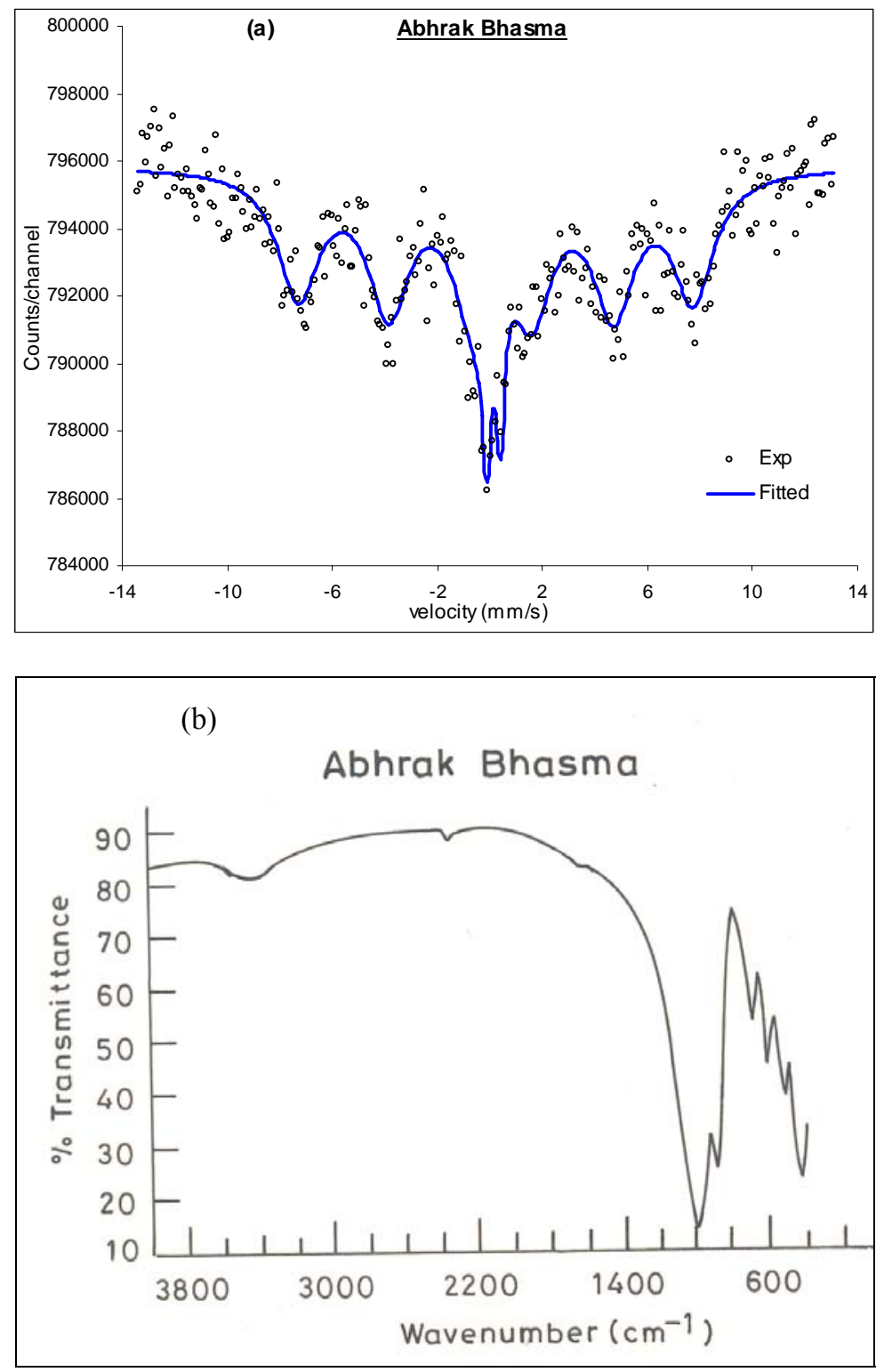

Figure 5. Mössbauer and FTIR Spectra of Abhrak bhasma

\section{Conclusions}

1. Three different bhasmas, namely, Lauh bhasma, Swarna Makshik bhasma and Abhrak bhasma have different compositions and size distribution of their particles.

2. While most of the iron in the Lauh bhasma shows fully grown $\mathrm{Fe}_{2} \mathrm{O}_{3}$ phase. Swarn Makshik and Abhrak (mica) seems to inhibit the formation and growth of $\mathrm{Fe}_{2} \mathrm{O}_{3}$ particles. Swarna Makshik bhasma shows heterogeneous phase formation. Iron shows up in at least three groups, fully grown, semi grown and very fine particles. Abarak bhasma does not show full grown particles of any phase, at the same time, it is larger in particle size than the nanosize component of Swarn Makshi bhasma.

3. FTIR spectra of all the drugs show peaks in the range 400-500 nm which is characteristic of iron-oxide. However samples show peaks in the other wavelength range such as $1000-2000 \mathrm{~cm}^{-1}$ or $2300-2500 \mathrm{~cm}^{-1}$. Lauh bhasma of different heating cycles, shows difference in these extra peak positions. These peaks correspond to the base matrix probably consisting of ash of herbs or compounds used as a medium for the preparation of these medicines. Nature of this base material is different for different drugs and may play a significant role in the process through which iron is disseminated in the system. 
This report must be seen as a rudimentary attempt to initiate a process to understand the chemical phases in some of the common iron-containing Ayurvedic medicines. It is a very intricate area of research as the processes involved in actions of medicines on human bodies must depends on number of parameters, not simply the chemical reactions. Ayurvedic system of medicine especially takes care of the conditioning of mind and interaction with the environment as evident from the prescribed specific life style while undergoing treatment. A well planned long term research can possibly make our understanding of the working of this system enriched.

\section{References}

Tripathi, A.M., Bhatia, B.D. and Agarwal, K.N., 1975. Nutritional anemias in childhood: a decade of progress in India. Ind. Pediatrics, Vol.12, No.4, pp. 343-349.

Charak Samhita-Sutra Sthana (Ancient Book, written by Charak)

Sushruta Samhita-Sharir Sthana (Ancient Book, written by Charak)

Tominaga, T. and Minai, Y., 1984. Applications of Mössbauer spectroscopy to environmental and geochemical studies. Nucl. Sci. Appl., Vol.1, pp.749- 791.

Mørup, S., Frank, J., Wontergham, J., Poulsen, R. H. and Larsen, L., 1985. Mössbauer spectroscopy study of the chemical state of iron in Danish Mesozoic sediments. Fuel, Vol.64, pp. 528-539.

Palanivel, R. and Velraj, G., 2007. FTIR and FT-Raman spectroscopic studies of fired clay artifacts recently excavated in Tamilnadu, India. Indian Journal of Pure \& Applied Physics, Vol.45, pp. 501-508.

Tripathi, R.P., Chandra, U., Chandra, R., and Lokanathan, S., 1978. A Mössbauer study of the effect of heating biotite, phlogopils and vermiculite. J. Inorg. Nucl. Chem., Vol. 40, pp.1293-1298.

\section{Biographical notes}

Amita Tripathi is working as geophysicist in Geological Survey of India, WR, Jaipur. She is M.Sc, Ph.D and trained geophysicist. She did her Ph.D in Mössbauer Spectroscopy and thereafter carried out research work as Research Associate (CSIR). She utilized this technique in study of various geological samples like meteorites, samples from various mass extinction boundaries, source rock samples from various petroliferous basin of India, samples from craters and magnetic particles etc. She has published 16 papers in national, international journals and conferences.

Bhavna Joshi did her M.Sc (Physics) from J.N.V. University, Jodhpur and presently working as a research scholar in Department of Physics, J.N.V. University.

H.S. Singh is working as Assistant Professor in Department of Physics, J.N.V. University. He has been engaged in teaching and research activities since the last 20 years. His field of specialization is Mössbauer Spectroscopy. He published papers in various national, international conferences and journals.

J.S. Rathore is working as Assistant Professor in Department of Chemistry, J.N.V. University. He has been engaged in teaching and research activities since last 18 years. His field of research is Environmental Chemistry with special reference to arid regions. He is currently engaged in investigation of metal and natural organic compound interactions using modern analytical techniques and engaged in analytical method development for chemical species in the environment. He has guided five students for Ph.D. He has published papers in various journals and conferences.

Giriraj Sharma is a medical doctor working at $\mathrm{CHC}$, Rohat. He has handled World Bank project and has almost 10 years experience in preventive medicines. He is inclined towards research and working on comparative study of allopathic and AYUSH heamatinics.

Received August 2010

Accepted October 2010

Final acceptance in revised form October 2010 